\title{
Spontaneous Intratesticular Haemorrhage
}

\begin{tabular}{|l|l|l|}
\hline P. & Per & Ovesen \\
\hline S. & Søren & Mommsen \\
\hline
\end{tabular}

Department of Urology K, Aarhus University Hospital, Aarhus, Denmark

\section{Key Words}

\section{Testis}

Spontaneous haematoma

Intratesticular haemorrhage

\section{Abstract}

Spontaneous intratesticular haemorrhage is a rare disease. Four cases have been described, all diagnosed after orchidectomy. We present an additional patient with a spontaneously arisen intratesticular haematoma in whom orchidectomy could be avoided.

Søren Mommsen, MD, Department of Urology, Aarhus Kommunehospital, DK-8000 Aarhus C (Denmark)

\section{Introduction}

Spontaneous intratesticular haemorrhage is a very rare disease. With an intratesticular mass and/or tenderness of the testicle the diagnosis testicle tumour should always be considered, especially in young men. We report a patient in whom the objective examination, ultrasound scanning, and surgical exploration suspected a tumour of the testicle. However, the diagnosis appeared to be spontaneously arisen intratesticular haematoma.

\section{Case Report}

A 25-year-old man was hospitalized preceded by 2 weeks of progressive pain in the left testicle as the only symptom. He had no previous trauma of the scrotum and no symptoms or diseases in the external and internal genitalia. On examination he had no fever and no redness or swelling of the left scrotum could be seen. Both testicles were of normal size and consistency, positioned normally in the scrotum, and were without perceptible tumours. The patient indicated intense pains by palpation of the testicle. Ultrasound scanning of the scrotum revealed an echo-poor mass of $15 \times 8 \times 8 \mathrm{~mm}$ (fig. 1) localized in the left testicle. Surgery revealed a testicle of normal form, size, and position. In agreement with the findings of ultrasound scanning, a thickened area was palpated. A small haematoma was evacuated. Microscopic examination of the haematoma wall revealed no malignancy, as only bleeding in the surrounding tissue was found. 


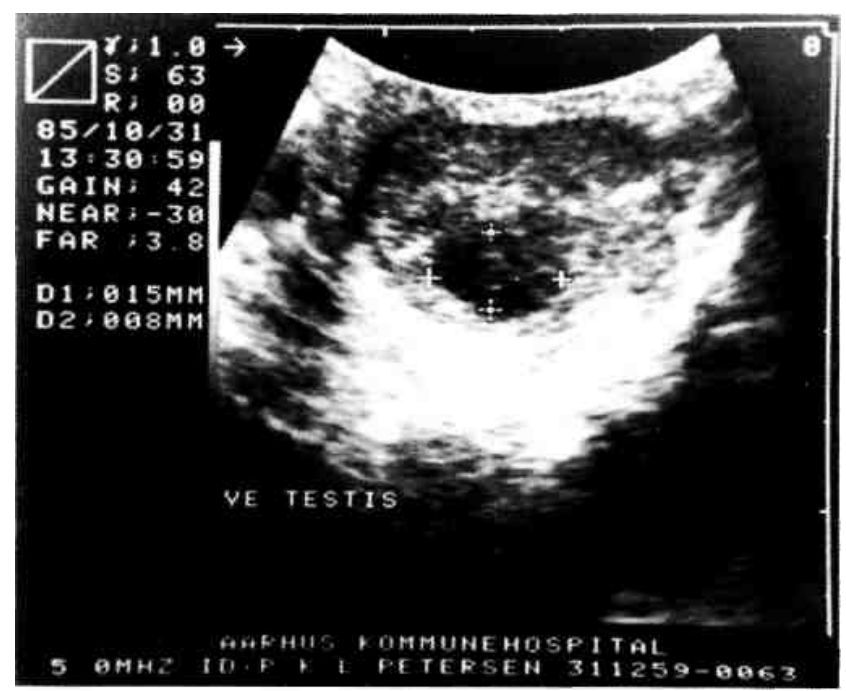

Fig. 1. Between crosses an echo-poor mass is localized.

Discussion

Only 4 cases of spontaneous intratesticular haemorrhage have previously been described. Evans et al. [1] reported a 28-year-old man with an untender enlargement of a testicle in whom the objective examination revealed one of the testicle a little larger than the other 108

Ovesen/Mommsen

one. By ultrasound scanning a 1.5-cm echo-poor area was detected. The diagnosis spontaneous intratesticular haemorrhage was established after orchidectomy and histological examination. Altaffer and Steele [2] who reported 74 cases of scrotal exploration, all revealing benign diseases, found 2 cases with intratesticular hae-matoma in whom the diagnosis was made after orchidectomy. No suggestions concerning the pathogenesis were described. Belville et al. [3] reported a patient with suddenly arisen pains and swelling of a testicle, while lifting, and in whom a haemorrhagic infarct and necrotizing vasculitis could be histologically demonstrated after orchidectomy.

The present case is the first published where the patient escaped orchidectomy and the diagnosis established perioperatively by biopsies from the suspected area. In spite of new diagnostic tools, it might still be difficult to distinguish malignant from benign intratesticular masses.

\section{References}

Evans KJ, Teddi RJ, Weatherby E: Spontaneous intratesticular hemorrhage masquerading as a testis tumor. J Urol 1985; 134 :

1211.

Altaffer LF III, Steele SM Jr: Scrotal explorations negative for malignancy. J Urol 1980;124:617-619.

Belville WD, Insalaco SJ, Dresner ML, Buck AS: Benign testis tumors. J Urol 1982;128:1198-1200. 